\title{
Keeping it Safe: Your Home's Electric System ${ }^{1}$
}

Mary N. Harrison ${ }^{2}$

\section{Electric Circuits}

The electrical power in your home is divided into several units called electric circuits. For example, your bathroom and kitchen may be on one electric circuit. The bedrooms may be on another electric circuit. That is the reason that sometimes the light may "go out" in the bedroom, but not in the kitchen.

When too many appliances are used at one time on one circuit, it will be overloaded. If equipment or the wiring in the house has been damaged there may be a "short circuit," which is an extremely dangerous overload. If you have any questions or concerns, call someone to help you.

\section{Circuit Breakers in Electric Control Box}

A circuit breaker protects a house from over-load by tripping a switch before an electrical wire reaches a dangerous temperature.

Your electrical control box (Figure 1) has one circuit breaker for each circuit in your house.

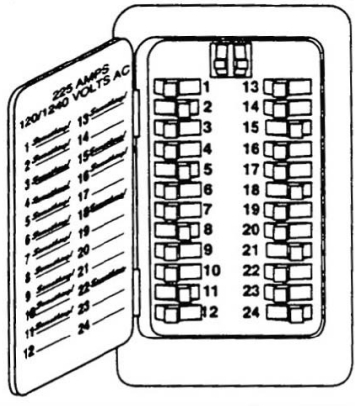

Figure 2.

Look at your electrical control box. Are the circuits labeled? If not, you need to label each circuit yourself. Here is how:

- Turn off one circuit breaker a switch at a time.

- Go through the house with a lamp to plug into outlets and check which outlets and appliances are not working.

- Those outlets and appliances are on the same circuit.

- Label that circuit in your circuit breaker box.

- Repeat for each circuit breaker switch.

1. This document is FCS5233-01, one of a series of the Department of Family, Youth and Community Sciences, Florida Cooperative Extension Service, Institute of Food and Agriculture Sciences, University of Florida. Publication: May 2002. Revised: December 2005. Please visit the EDIS Web site at http://edis.ifas.ufl.edu.

2. Mary N. Harrison, professor, Department of Family, Youth and Community Sciences, Cooperative Extension Service, Institute of Food and Agricultural Sciences, University of Florida, Gainesville, 32611.

The Institute of Food and Agricultural Sciences (IFAS) is an Equal Opportunity Institution authorized to provide research, educational information and other services only to individuals and institutions that function with non-discrimination with respect to race, creed, color, religion, age, disability, sex, sexual orientation, marital status, national origin, political opinions or affiliations. U.S. Department of Agriculture, Cooperative Extension Service, University of Florida, IFAS, Florida A. \& M. University Cooperative Extension Program, and Boards of County Commissioners Cooperating. Larry Arrington, Dean 


\section{Power Outage}

If your electrical power goes off in one part of your home check the circuit breakers in your electrical control box. Find the circuit breaker for that part of your house. Switch the circuit breaker to "off" and then back to "on." If the problem persists, unplug one appliance. The circuit may be overloaded. Switch the circuit breaker back on.

If the entire house is without power and no circuit breaker is turned off it may be a general power outage. You may need to call the power company.

\section{Ground Fault Circuit Interrupters (GFCls)}

GFCIs are designed to protect people from a shock that can happen before a circuit breaker switches off. For example, a curling iron dropped in a bathtub will electrocute a bather. Even a circuit breaker cannot act fast enough to help. New homes are required to have GFCIs in bathrooms, garages and outside outlets to protect people from accidents like the one above. Most commonly, a GFCI is installed in place of a conventional grounded circuit and can protect all outlets on the circuit. If any outlet on that circuit is not working, the GFCI reset button (in the circuit box or on one of the outlets) can turn the electricity back on.

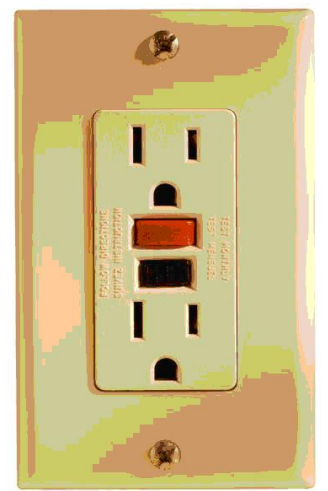

Figure 1. the reset button is visible in the middle of the outlet.

\section{Smoke Detectors}

How does your smoke detector work?
- Battery-powered smoke detectors are powered by a battery that should be replaced every year. A good plan is to change your smoke detector battery every fall when you change your clocks back to standard time or on New Years Day. Whatever your choice, pick a day and stick with it. An alkaline battery is the best type to use.

- Hard-wired smoke detectors are connected to the houses electrical system. If smoke is detected in one part of the house, all alarms will sound. The detector will not work if the electricity is turned off or is interrupted.

You should check your smoke detector regularly to be sure it is working.

Test the alarm by pressing the test button firmly for five (5) seconds. The alarm will sound. 